\title{
Исследование доходности фондов прямых инвестиций (на примере развитых рынков капитала)
}

\author{
Пархоменко А.B. ${ }^{4}$
}

В рамках данной статьи мы тестируем гипотезу о том, что менеджеры завышают или повышают оченку чистой стоимости активов существующего фонда перед открытием нового фонда. Причиной стремления менеджеров к завышению или повышению чистой стоимости активов существующего фонда перед открытием нового может быть либо желание привлечь больше средств для нового фонда (завышение ЧСА), либо эндогенность процесса открытия нового фонда. В результате только одна гипотеза соответствует наблюдаемым данным (завымение ЧСА) модели.

JEL: G10; $G 20$

Ключевые слова: фонды прямых инвестиций, венчурные фонды, оценка активов, корпоративное развитие, компенсаиия менеджмента

\section{Введение}

Вложения в фонды прямых инвестиций (ФПИ), если их сравнивать с инвестициями в публичные активы (акции и облигации публичных компаний), отличаются дополнительными проблемами, возникающими в силу наличия асимметрии информации, по крайней мере, в трех аспектах.

Во-первых, ФПИ напрямую не регулируются классическими институтами финансового мониторинга и контроля, такими как Комиссия по ценным бумагам в США или Федеральная служба по финансовым рынкам в России, которые призваны бороться с асимметрией информации. Напротив, почти все отношения между менеджерами фондов ${ }^{5}$ (агентами) и инвесторами (принципалами) ${ }^{6}$ являются практически полностью контрактными, т.е. регулируются заключаемыми между ними соглашениями. Учитывая, что полные контракты на практике нереализуемы, инвесторы и менеджеры сталкиваются с риском остаточных обязательств, не охваченных контрактом. Причем в контексте ФПИ инвестор находится в более невыгодном положении, поскольку менеджер обладает большей властью в фонде и способен манипулировать степенью раскрытия информации и мер доходности, стратегически выбирать время для инвестиций и т.д.

Во-вторых, существует проблема компетентности инвесторов. Ввиду исключительной сложности и нестандартности контрактов между инвесторами и менеджерами далеко не каждый квалифицированный инвестор понимает и осознает все последствия и риски, связанные с инвестированием в ФПИ. Это может быть связано как с когнитивными ограничениями самих инвесторов и «поведенческими» особенностями инвестирования, так и со стандартами раскрытия информации и измерения доходности в рамках ФПИ, которые только усугубляют проблему асимметрии информации и постконтрактного оппортунизма.

В-третьих, эти стандарты, в свою очередь, не отвечают требованиям инвесторов и

\footnotetext{
${ }^{4}$ Стажёр-исследователь научно-учебной Лаборатории корпоративных финансов ГУ-ВШЭ. Данная статья является частью магистерской диссертации, написанной в рамках программы двойных дипломов ГУ-ВШЭ и Амстердамской бизнес-школы (АБШ). Научный руководитель от ГУ-ВШЭ - Ивашковская И.В., проф. ГУВШЭ, канд.эконом.наук, зав. кафедрой ЭФФ. Научный руководитель со стороны АБШ - Людовик Фалиппу, профессор АБШ, Ph.D.

5 Другое название, получившее распространение в англосаксонской правовой традиции, - генеральный партнер (GP, general partner).

${ }^{6}$ Другое название - ограниченный партнер (LP, limited partner).
}

Выпуск \#4(8), 2008 (C) Электронный журнал Корпоративные Финансы, 2008 
полностью не отражают эффективность или неэффективность деятельности ФПИ. Фалиппу [Phalippou, 2008] показал, что внутренняя ставка доходности (IRR, internal rate of return), одна из основных мер прибыльности инвестиций в ФПИ, характеризуется рядом существенных недостатков (предпосылка о реинвестировании и эндогенные денежные потоки). Помимо этого менеджеры часто публикуют информацию о своей доходности так, что инвесторы не могут оценить эффективную ставку доходности ${ }^{7}$. При отсутствии единого стандарта измерения доходности проблема компетентности инвесторов и асимметрии информации ведет к неоптимальному выбору: при отсутствии стандарта инвестор не может правильно определить ни долю инвестиций в ФПИ как класс активов, ни правильно выбрать фонды для инвестирования. В таких условиях менеджеры имеют преимущество перед инвесторами и способны реализовать его в виде большей комиссии и пр. Только очень опытные инвесторы способны заставить менеджеров раскрыть больше информации и правильно сделать выбор относительно фондов.

В рамках данной статьи мы тестируем гипотезу о том, что менеджеры завышают или повышают оценку чистых активов существующего фонда перед открытием нового фонда. Чистые активы (NAV, net asset value) - разница между оценкой стоимости всех активов фонда и величиной долга фонда. До 2004 года ФПИ на развитых рынках капитала самостоятельно оценивали свои активы раз в квартал. Данные оценки не подлежали внешнему аудиту, фонды использовали те методики оценки и выборки фондов, которые они считали наиболее подходящими.

Причиной стремления менеджеров к завышению или повышению ЧСА существующего фонда перед открытием нового может быть либо желание привлечь больше средств для нового фонда (завышение ЧСА), либо эндогенность процесса открытия нового фонда. В первом случае менеджеры стремятся завысить ЧСА, с тем чтобы инвесторы поверили, что менеджеры обладают навыками, необходимыми для эффективного управления фондом. В этом случае, при прочих равных условиях, менеджеры могут привлечь больше средств в новый фонд. Этим самым они увеличивают свою компенсацию, которая зависит от величины капитала под управлением. Во втором случае, решение открыть новый фонд принимается в том случае, если существующий фонд (или фонды) являются прибыльными. Иначе говоря, сначала существующий фонд становится успешным, в результате менеджмент увеличивает оценку ЧСА и принимает решение об открытии нового фонда.

Целью данной статьи является анализ причин наблюдаемого повышения чистой стоимости активов существующих фондов перед открытием нового фонда.

\section{1. Особенности ФПИ}

Фонды прямых инвестиций являются частными партнерствами, в которых отношения между партнерами (т.е. менеджерами и инвесторами) регулируются эксплицитными контрактами. Учитывая сложную институциональную среду, в которой существуют ФПИ, контракты зачастую оказываются крайне нестандартными и комплексными. Это делает ФПИ особым инструментом инвестирования в рамках финансового рынка.

Инвесторами в большинстве случаев выступают институциональные инвесторы: пенсионные фонды, страховые компании, эндаументы и банки. Эти инвесторы называются ограниченными партнерами (LP, limited partners), они предоставляют капитал ФПИ, которые управляются менеджерами или генеральными партнерами (GP, general partners). После того как инвесторы подписали контракт с менеджерами, менеджеры подбирают активы или проекты для инвестирования и после этого привлекают деньги инвесторов. Финансирование происходит в несколько раундов (число которых зависит от степени привлекательности проекта и успешности поиска инвесторов). После того как инвестиции реализуются

\footnotetext{
7 Примером манипуляции доходностью фонда являются скрытие метода расчета, использование в выборке только фондов с удачными инвестициями, агрегирование показателей, недораскрытие информации и пр.

Выпуск \#4(8), 2008

(C) Электронный журнал Корпоративные Финансы, 2008
} 
(происходит размещение доли ФПИ на публичном рынке или продажа частному инвестору), менеджеры распределяют дивиденды среди инвесторов. Фонды бывают нескольких типов, в зависимости от типа сделки и объекта инвестирования. Наиболее распространенными типами являются венчурные фонды, которые инвестируют в инновационные компании, и фонды выкупа, которые концентрируются на сделках по выкупу, как правило, состоявшихся компаний с использованием долговых инструментов. Средний срок жизни подобного фонда составляет 7-12 лет, причем каждые 3-5 лет менеджеры открывают новый фонд.

При этом график движения денежных средств изначально не определен. Инвесторы (впрочем, как и менеджеры), подписывая контракт, не знают точно, когда придется непосредственно предоставлять деньги для инвестирования. Более того, у ФПИ жестко не зафиксирован график реализации инвестиций и срок жизни фонда ${ }^{8}$.

Контракты, как правило, состоят более чем из 100 страниц и являются крайне сложными для прочтения и понимания. Инвесторы имеют ограниченную возможность влияния на принятие решения менеджерами. Частично это компенсируется информационными правами - возможностью мониторинга деятельности фонда и дискуссий с менеджментом на регулярной основе.

Помимо этого в контракте, как правило, закладываются дополнительные условия (covenants), при помощи которых инвесторы пытаются решить проблему постконтрактного оппортунизма. Существует несколько классов условий 9 : ограничение величины инвестиций в одну компанию, ограничение величины долга, ограничение возможностей соинвестирования с другими фондами, правила реинвестирования прибыли, ограничение продажи части активов, ограничение на инвестирование в публичные активы и пр.

Раскрытие информации в рамках индустрии ФПИ является крайне интересной темой для экономической теории. Классическим результатом финансовой экономики является вывод о существовании равновесия в модели с сигналами, когда более сильные игроки эффективно сигнализируют о своем преимуществе неосведомленному игроку. Мы можем представить, что неудачные менеджеры будут стараться недораскрыть информацию о своей деятельности и доходности, но успешные менеджеры имеют все стимулы для позиционирования себя как более успешного фонда. В реальности ФПИ славятся своей закрытостью и непрозрачностью: до 2002 года, когда был выигран иск против фонда CalPERS, информация о доходности фонда и компенсации менеджеров была закрытой в США.

Одной из интересных гипотез, способных объяснить феномен недораскрытия информации, является предположение о наличии альтернативных каналов сигнализирования - публикация информации о лучших и сверхдоходных инвестициях в СМИ. Истории венчурных фондов самые показательные в этом смысле - почти каждый знает о грандиозном успехе таких проектов, как Google, Skype или Yahoo, которые финансировались ФПИ.

Другая гипотеза заключается в том, что ФПИ стараются не разглашать информацию о себе с целью ограничения объема капитала при подписке, поскольку издержки отказа от инвестиций велики. При этом возникает другой вопрос - если фонд ожидает наличие излишнего капитала от инвесторов при подписке, почему бы не увеличить размер компенсации за услуги?

Структура компенсации менеджеров состоит из двух главных элементов - платы за управление (management fee) и участие в прибыли (carry). Плата за управление является фиксированной составляющей и взимается, как правило, с инвестированного капитала. Участие в прибыли является формой мотивации менеджмента и рассчитывается на базе разницы между ценой продажи актива при выходе и инвестициями в него. Эффективный

\footnotetext{
${ }^{8}$ Как правило, срок жизни фонда оговаривается. Типичный срок - 10 лет, но при этом у менеджеров, как правило, есть возможность продлить срок жизни фонда на $1-3$ года.

${ }^{9}$ Классификация взята из работы Гомперза и Лернера [Gompers and Lerner, 1996].
}

Выпуск \#4(8), 2008

(C) Электронный журнал Корпоративные Финансы, 2008 
уровень компенсации определить крайне сложно, поскольку договор между инвестором и менеджером является очень сложным, а в отношении будущего существует огромная неопределенность.

\section{2. Данные и описательная статистика}

В своем исследовании мы используем раздел «cash-flows» базы данных Thomson Venture Economics (TVE). Она содержит информацию о величине и дате всех потоков денежных средств инвестору и от инвестора, а также квартальные данные о чистой стоимости активов (net asset values, далее - ЧСА); период 1980-2003 годов. База также содержит различные характеристики ФПИ: размер, инвестиционный (фонды выкупа или венчурные инвестиции) и географический фокусы (США или Европа). Более ранние версии этой базы данных были использованы в исследованиях Каплана и Шора [Kaplan and Schoar, 2005] и Фалиппу и Готсхальга [Phalippou and Gottschalg, 2006]. Данная база, являясь самой обширной базой данных по ФПИ, служит основой для отраслевых стандартов доходности, публикуемых TVE и прочими ассоциациями. Основой сведений о денежных потоках для нее служат добровольно распространяемая инвесторами информация, а о стоимости чистых активов - аудированные финансовые отчеты партнерств.

Мы начинаем наш анализ с изучения изменений чистой стоимости активов во времени. В таблице 1 представлена динамика ЧСА в течение жизни фонда: средние и медианные изменения ЧСА невелики в первые и последние годы жизни и достигают максимума между третьим и восьмым годами существования фонда. Одним из возможных объяснений является гипотеза о том, что перед открытием нового фонда (которое, как правило, происходит раз в три-пять лет) фирмы начинают увеличивать свою ЧСА.

В таблице 2 приведены сведения об изменении ЧСА в момент открытия нового фонда одной и той же фирмой. Согласно приводимым данным, за год до открытия нового фонда ЧСА предыдущего фонда резко увеличивается: средний рост составляет до $12,75 \%$ за год, против контрольного роста в $9.07 \%{ }^{10}$. Аналогично после открытия нового фонда наблюдается резкое снижение ЧСА: через год после открытия - 7,33\% (среднеарифметическое) против контрольных 9,07\%.

Хотелось бы отметить свойства распределения ЧСА (точнее - ее изменений), представленных в таблице 1. Показатели распределения 3-го и 4-го моментов (асимметрия и эксцесс) таковы, что распределение ЧСА характеризуется тяжелым правым хвостом (положительный показатель асимметрии) и излишним эксцессом (больше 3). Первый показатель говорит о том, что существует ограниченное число очень успешных фондов«звезд» (например, Google), которые резко наращивают ЧСА ввиду своего успеха - это прежде всего венчурные фонды, основная масса инвестиций в которые обладает умеренной или отрицательной прибыльностью. Излишний эксцесс (больше 3) содержательно свидетельствует о наличии значительного числа фондов с малыми изменениями ЧСА. Среднеарифметическое, как мера среднего, крайне чувствительно к экстремальным значениям (выбросам), которые в данном случае выражены в нескольких «звездах» в выборке, поэтому имеет смысл использовать медиану и прочие меры, более устойчивые к выбросам.

Действительно, картина выглядит еще более убедительной при использовании медианы, которая, как мера среднего, менее чувствительна к выбросам. Так, по представленным данным можно заметить, что за год до открытия нового фонда изменение ЧСА составляет 4,97\%, при контрольном росте $1,28 \%$. Аналогично через год после открытия нового фонда - 0,43\% против контрольных $1,28 \%$.

\footnotetext{
${ }^{10}$ Контрольный рост - среднее изменение ЧСА, рассчитанное по выборке фондов за пределами 3 лет до и после открытия нового фонда.
}

Выпуск \#4(8), 2008

() Электронный журнал Корпоративные Финансы, 2008 
Таблица 1

\section{Описательная статистика}

\begin{tabular}{|c|c|c|c|c|c|c|c|c|c|c|}
\hline \multirow{2}{*}{$\begin{array}{c}\text { Возраст } \\
\text { фонда, } \\
\text { год } \\
\end{array}$} & \multicolumn{2}{|c|}{$\Delta$ ЧСА, $\%$} & \multicolumn{2}{|c|}{ Дивиденды, \% } & \multicolumn{2}{|c|}{$\Delta$ ЧCA } & \multirow{2}{*}{$\begin{array}{c}\text { ЧСА } \\
\text { Всего, } \\
\text { тыс. } \\
\text { долл. }\end{array}$} & \multirow{2}{*}{$\begin{array}{c}\text { PMV } \\
\text { Всего, } \\
\text { тыс. } \\
\text { долл. }\end{array}$} & \multirow{2}{*}{$\begin{array}{c}\text { DMV } \\
\text { Всего, } \\
\text { тыс. } \\
\text { долл. }\end{array}$} & \multirow{2}{*}{$\begin{array}{c}\begin{array}{c}\text { Число } \\
\text { фондов }\end{array} \\
\text { Всего }\end{array}$} \\
\hline & Средняя & Медиана & Средняя & Медиана & $\begin{array}{l}\text { Асимметрия } \\
\text { (skewness) }\end{array}$ & $\begin{array}{l}\text { Эксцесс } \\
\text { (kurtosis) }\end{array}$ & & & & \\
\hline 1 & 7.8 & 0.7 & 9.1 & 0.0 & 1.4 & 6.3 & 110241 & 174448 & 108046 & 1579 \\
\hline 2 & 6.5 & 1.0 & 11.9 & 1.3 & 1.5 & 7.1 & 122511 & 171671 & 118030 & 1500 \\
\hline 3 & 6.3 & 1.0 & 15.0 & 4.5 & 1.1 & 5.7 & 111528 & 149399 & 105864 & 1351 \\
\hline 4 & 8.1 & 2.4 & 17.2 & 7.2 & 1.3 & 6.1 & 91595 & 121055 & 87963 & 1184 \\
\hline 5 & 8.2 & 2.2 & 20.0 & 9.1 & 1.2 & 6.0 & 72648 & 96435 & 70587 & 1067 \\
\hline 6 & 9.5 & 2.6 & 22.7 & 10.4 & 1.3 & 5.6 & 56033 & 71178 & 53857 & 929 \\
\hline 7 & 9.7 & 2.8 & 26.5 & 15.4 & 1.3 & 5.9 & 41052 & 51770 & 39015 & 817 \\
\hline 8 & 8.1 & 2.1 & 27.4 & 17.3 & 1.3 & 6.3 & 29002 & 36376 & 27466 & 730 \\
\hline 9 & 7.6 & 0.2 & 29.1 & 15.2 & 1.1 & 5.1 & 19314 & 24485 & 18600 & 594 \\
\hline 10 & 9.8 & 2.4 & 30.6 & 17.7 & 1.3 & 5.7 & 13253 & 16793 & 13642 & 488 \\
\hline $11+$ & 5.9 & 0.0 & 28.2 & 1.3 & 1.5 & 7.0 & 28295 & 32037 & 28477 & 115 \\
\hline
\end{tabular}

Таблица 2

\section{Описательная статистика}

\begin{tabular}{|c|c|c|c|c|c|c|c|c|c|c|}
\hline \multirow{3}{*}{$\begin{array}{c}\text { Время до/после } \\
\text { ближайшего } \\
\text { открытия } \\
\text { нового фонда } \\
\end{array}$} & \multirow{2}{*}{\multicolumn{2}{|c|}{$\frac{\Delta \text { ЧСА, } \%}{\text { Включая дивиденды }}$}} & \multirow{2}{*}{\multicolumn{2}{|c|}{$\begin{array}{c}\Delta \text { ЧСА, } \% \\
\text { Исключая } \\
\text { дивиденды }\end{array}$}} & \multirow{2}{*}{\multicolumn{2}{|c|}{ Дивиденды, \% }} & \multirow{3}{*}{$\begin{array}{c}\text { NAV } \\
\text { Всего, } \\
\text { тыс. долл. }\end{array}$} & \multirow{3}{*}{$\begin{array}{c}\text { PMV } \\
\text { Всего, } \\
\text { тыс. долл. }\end{array}$} & \multirow{3}{*}{$\begin{array}{c}\text { DMV } \\
\text { Всего, } \\
\text { тыс. долл. }\end{array}$} & \multirow{3}{*}{$\begin{array}{r}\begin{array}{r}\text { Число } \\
\text { фондов }\end{array} \\
\text { Всего }\end{array}$} \\
\hline & & & & & & & & & & \\
\hline & Средняя & Медиана & Средняя & Медиана & Средняя & Медиана & & & & \\
\hline-3 года & 2.69 & 0.31 & -7.58 & -1.66 & 10.27 & 6.44 & 863 & 1863 & 606 & 143 \\
\hline -2 года & 6.88 & 2.28 & -2.90 & 0.00 & 9.78 & 0.85 & 7187 & 16873 & 7912 & 206 \\
\hline-1 год & 12.75 & 4.97 & -7.51 & -0.94 & 20.26 & 6.44 & 53224 & 111270 & 61210 & 1026 \\
\hline +1 год & 7.33 & 0.43 & -8.79 & -4.27 & 16.12 & 2.46 & 178496 & 242456 & 166522 & 2607 \\
\hline+2 года & 6.83 & 0.49 & -9.98 & -5.80 & 16.80 & 4.57 & 46926 & 74592 & 46564 & 1013 \\
\hline+3 года & 9.36 & 2.46 & -13.35 & -6.42 & 22.70 & 9.64 & 20455 & 36471 & 25240 & 515 \\
\hline Вне интервала $^{11}$ & 9.07 & 1.28 & -13.73 & -5.38 & 22.81 & 5.73 & 54224 & 93688 & 62688 & 1799 \\
\hline
\end{tabular}

\section{3. Методология}

Существует несколько гипотез, способных объяснить поведение ЧСА, описанное в предыдущем разделе. Согласно гипотезе А («хорошие новости») фирмы увеличивают ЧСА существующего фонда тогда, когда появляются «хорошие новости». Это увеличение ЧСА позволяет фирмам открывать новые фонды, привлекая достаточное количество капитала. Гипотеза В («манипулирование инвесторами») предполагает, что менеджеры стратегически устанавливают ЧСА таким образом, чтобы, изменяя мнение инвесторов, привлечь больше капитала для нового фонда.

Гипотеза А («хорошие новости»)

- A1: рассматривать ЧСА как рыночную стоимость инвестиций. Мы предполагаем, что менеджеры каждый квартал оценивают ЧСА по рыночной стоимости, т.е. исходя из будущих денежных потоков. Следовательно, ЧСА отражает всю доступную информацию и ожидания о будущем данного актива.

\footnotetext{
${ }^{11}$ См. либо 3 года до, либо 3 года после открытия фонда.
}
Выпуск \#4(8), 2008
(C) Электронный журнал Корпоративные Финансы, 2008 
- А2: рассматривать ЧСА фонда как ЧСА паевого фонда, которая учитывает только ликвидационную стоимость фонда и текущую стоимость на рынке и игнорирует возможность создания (разрушения) стоимости благодаря эффективному менеджменту и проч.

- А3: ЧСА включает только издержки, если только не происходит никаких рыночных событий, при которых ЧСА обновляется для отражения текущей рыночной стоимости. Таким образом, в отсутствие подобных обновлений ЧСА является консервативной или в среднем «недооцененной».

Гипотеза В («манипулирование инвесторами»)

- В1: менеджеры всегда преувеличивают ЧСА, чтобы ввести инвесторов в заблуждение. Следовательно, фонды всегда обманывают инвесторов, в особенности раздувая ЧСА перед сбором средств.

- В2: менеджеры никогда не говорят о плохих событиях, но всегда рады быстро сообщить хорошие новости. Следовательно, они никогда не пересматривают ЧСА в сторону понижения, в особенности перед привлечением новых средств. Однако, если у них есть некоторые позитивные ожидания, фонды весьма быстро пересмотрят ЧСА в сторону повышения, опять же, в особенности перед привлечением новых средств.

Для определения того, какая гипотеза является верной, мы изучаем три аспекта: 1) детерминанты ЧСА; 2) детерминанты премии ${ }^{12}$ к ЧСА; 3) размер нового фонда. Предсказания для двух конкурирующих гипотез представлено в таблице 3. Далее мы разбиваем основные гипотезы А и В на 5 более мелких.

\section{Детерминанты ЧСА}

Ниже представлена панельная регрессионная модель детерминант ЧСА:

$$
\Delta N A V_{i t}=\alpha+\beta \cdot \Delta N A V_{i t-1}+\gamma F R_{i t}+\theta S P_{t}+\eta C_{i t}+\varepsilon_{i t}^{1},
$$

где

$\Delta N A V_{i t}$ и $\triangle N A V_{i t-1}$ — изменение ЧСА $i$-го фонда в год $t$ и $t$ - 1 соответственно;

$F R_{i t}$ - бинарная переменная открытия нового фонда;

$S P_{t}$ — доходность индекса S\&P 500 за год $t$;

$C_{i t}$ - другие контролирующие переменные (см. таблицу 4).

Главный вопрос заключается в оценке коэффициента перед $\triangle N A V_{i t-1}$. Возможны следующие варианты и их толкование в соответствии с выдвинутыми ранее гипотезами (в скобках указаны предполагаемые знаки коэффициента):

- $\mathrm{A} 1(=0)$ : отсутствие влияния, так как вся информация уже учтена в ЧСА;

- $\mathrm{A} 2$ (>0): растущая ЧСА является сигналом хорошего менеджмента, следовательно, это должно привести к росту ЧСА в будущем;

- А3 (< 0): если фонд ликвидируется, то его ЧСА обновляется до уровня, соответствующего цене ликвидации (продажи). ЧСА всех остальных фондов на рынке слишком низки;

- $\mathrm{B} 1(<0):$ ЧСА раздувается при организации нового фонда, следовательно, после этого может снижаться;

- В2 (> 0): одновременно действуют два разнонаправленных эффекта. Во-первых, другие фонды, не привлекающие новых средств, относительно переоценены, а

\footnotetext{
${ }^{12}$ Имеется в виду отношение «рыночной стоимости» активов к ЧСА. Под «рыночной стоимостью» понимается приведенный (по ставке S\&P 500) поток будущих дивидендов.
} 
фонды, привлекающие средства, следовательно, имеют относительно низкие ЧСА.

\section{Детерминанты премии к ЧСА}

Ниже представлена панельная регрессионная модель детерминант рыночного дисконта (премии) к ЧСА фонда:

$$
\log \left[\frac{M V}{N A V}\right]_{i t}=\alpha+\beta \cdot \Delta N A V_{i t-1}+\gamma F R_{i t}+\theta S P_{t}+\eta C_{i t}+\varepsilon_{i t}^{2},
$$

где

$M V_{i t}$ - рыночная цена ${ }^{13} i$-го фонда в год $t$;

$N A V_{i t}-$ ЧСА $i$-го фонда в год $t$;

$\Delta N A V_{i t-1}$ - изменение ЧСА $i$-го фонда в год $t$ - 1 ;

$F R_{i t}$ - бинарная переменная открытия нового фонда;

$S P_{t}$ — доходность индекса S\&P 500 за год $t$;

$C_{i t}$ — другие объясняющие переменные (см. таблицу 4).

Главный вопрос заключается в оценке коэффициента перед $\Delta N A V_{i t-1}$. Возможны следующие варианты и их толкование в соответствии с выдвинутыми ранее гипотезами (в скобках указаны предполагаемые знаки коэффициента):

- $\mathrm{A} 1$ (=0): отсутствие влияния;

- $\mathrm{A} 2$ (= 0): возросшая ЧСА (возникающая как результат хорошего менеджмента) должна быть учтена в будущем ЧСА;

- А3 (< 0): если фонд ликвидируется, то его ЧСА обновляется до уровня, соответствующего цене ликвидации (продажи). ЧСА всех остальных фондов на рынке слишком низки;

- $\mathrm{B} 1(<0)$ : «раздутие» ЧСА при привлечении средств должно привести к будущему падению (большему дисконту), так как оно не подкреплено фундаментальными причинами (ожиданиями будущих денежных потоков;

- $\mathrm{B} 2$ (>0): фонды без положительных write-ups, вероятно, и в будущем будут иметь меньше положительных write-ups.

\section{Размер новых фондов}

Ниже представлено уравнение регрессионной модели для размера новых фондов:

(3) Size $_{i}=\alpha+\beta \cdot \Delta P N A V_{i}+\gamma$ PSize $_{i}+v I R R_{i}+\phi P I R R_{i}+\eta C_{i}+\pi T E_{i}+\varepsilon_{i}^{3}$,

где

$S_{i z} e_{i t}$ — логарифм размера $i$-го нового фонда, который был открыт в год $t$;

$\Delta N A V_{i t-1}$ - изменение ЧСА $i$-го фонда в год $t$ - 1 ;

$I R R_{i t}$ - внутренняя ставка доходности фонда;

$P I R R_{i t}$ — внутренняя ставка доходности предыдущего фонда (если это первый фонд $-0)$

$\mathrm{PSize}_{i}$ — логарифм размера предыдущего фонда;

$C_{i}$ — другие объясняющие переменные (см. таблицу 4);

\footnotetext{
${ }^{13}$ Под рыночной ценой подразумевается поток будущих дивидендов, дисконтированный по ставке S\&P 500. 
$T E_{i}$ — матрица бинарных переменных времени (time effect).

Мы ожидаем следующие значения коэффициентов (указаны в скобках) по выдвинутым гипотезам А1-3, В1-2:

- $\mathrm{A} 1(>0 ;=0)$ : если изменение в ЧСА - свидетельство хорошего менеджмента, то размер нового фонда растет $(>0)$, если же нет — то не оказывает никакого эффекта на размер (0);

- $\mathrm{A} 2(>0 ;=0)$ : если изменение в ЧСА - свидетельство хорошего менеджмента, то размер нового фонда растет $(>0)$, если же нет - то не оказывает никакого эффекта на размер (0);

- $\mathrm{A} 3(<0):$ негативное влияние;

- $\mathrm{B} 1(>0 ; 0)$ : положительное влияние, если инвесторов обманывают $(>0)$, в большей части случаев эффект не наблюдается $(0)$;

- $\mathrm{B} 2(<0 ; 0)$ : отрицательное влияние, если инвесторов обманывают $(>0)$, в большей части случаев эффект не наблюдается (0).

Таблица 3

\section{Предсказания основных гипотез}

\begin{tabular}{|c|c|c|c|c|}
\hline Гипотеза & Подгипотеза & Детерминанты ЧСА & Детерминанты премии к ЧСА & Размер нового фонда \\
\hline \multirow{3}{*}{ Хорошие новости } & A1 & 0 & 0 & 0 или + \\
\hline & A2 & + & 0 & 0 или + \\
\hline & $\mathrm{A} 3$ & - & - & - \\
\hline \multirow[b]{2}{*}{$\begin{array}{c}\text { Манипулирование } \\
\text { инвесторами }\end{array}$} & B1 & - & 0 или - & Если обман,+ иначе 0 \\
\hline & $\mathrm{B} 2$ & + & + & Если обман - , иначе 0 \\
\hline
\end{tabular}


Таблица 4

\section{Описание переменных}

\begin{tabular}{|c|c|c|}
\hline Переменные & Модель & Комментарий \\
\hline Возраст фонда $(\log )$ & (1) (2) & $\begin{array}{l}\text { Логарифм возраста } i \text {-го фонда в год } t \text {. Возраст измерен в } \\
\text { месяцах с момента существования }\end{array}$ \\
\hline Размер фонда $(\log )$ & (1) (2) & Логарифм размера фирмы (менеджмента) в год $t$ \\
\hline Размер предыдущего фонда (log) & (3) & $\begin{array}{l}\text { Логарифм размера предыдущего фонда. Для } i \text {-го фонда в } \\
\text { год } t \text { находится предыдущей фонд той же фирмы. Если } \\
\text { первый фонд }-0 \text {. }\end{array}$ \\
\hline Размер фирмы (log) & (1) (2) & Логарифм размера фирмы (менеджмента) в год $t$ \\
\hline Последовательность фондов (log) & $(1)(2)(3)$ & $\begin{array}{l}\text { Последовательность фондов: сумма всех фондов } \\
\text { существующих у фирмы в момент } t \text {. Если у фирмы два } \\
\text { фонда, то последовательность } \\
3=1+2 \text {. Прокси для опыта. }\end{array}$ \\
\hline$\Delta$ ЧСA (t) & $(1)(2)(3)$ & $\begin{array}{l}\text { Изменение чистой стоимости активов } i \text {-го фонда в год } t \text { в } \\
\text { тыс. долл. }\end{array}$ \\
\hline Доходность фонда $(\log )$ & (1) $(2)$ & $\begin{array}{l}\text { Логарифм дивидендной доходности } i \text {-го фонда в год } t \text {. } \\
\text { Дивидендная доходность }- \text { сумма дивидендов, } \\
\text { выплаченных до года } t, \quad \text { к сумме вcех инвестиций, } \\
\text { выплаченных до года } t \text {. }\end{array}$ \\
\hline $\begin{array}{l}\text { Открытие фонда за n лет до (после) } \\
\text { (t) }\end{array}$ & (1) (2) & $\begin{array}{l}\text { Бинарная (дамми) переменная открытия нового фонда. } \\
\text { Равна единице если у } i \text {-го фонда в год } t \text {, за n лет до года } t \text {, } \\
\text { был открыт новый фонд. }\end{array}$ \\
\hline Доходность рынка акций (t) & $(1)(2)(3)$ & Индекс S\&P 500 \\
\hline Доходность рынка акций $(\mathrm{t})-$ рост & (1) (2) & $\begin{array}{l}\text { Равен индексу S\&P 500, если был рост индекса, ноль - в } \\
\text { противном случае. }\end{array}$ \\
\hline $\begin{array}{l}\text { Доходность отрасли ФПИ (Private } \\
\text { Equity) (t) }\end{array}$ & (1) (2) & $\begin{array}{l}\text { Средневзвешенная (по размеру фонда) доходность ФПИ. } \\
\text { Рассчитана на основе «Доходность фонда» }\end{array}$ \\
\hline $\begin{array}{l}\text { Доходность отрасли ФПИ (Private } \\
\text { Equity) (t) - рост }\end{array}$ & (1) (2) & Аналогичен «Доходность рынка акций $(\mathrm{t})-$ рост» \\
\hline Венчурный фонд & $(1)(2)(3)$ & 1 - если венчурный фонд, 0 в противном случае. \\
\hline Фонд из США & $(1)(2)(3)$ & $\begin{array}{l}1 \text { - если фонд инвестирует в США, } 0-\text { в противном } \\
\text { случае }\end{array}$ \\
\hline Первый фонд & $(1)(2)$ & 1 - если первый фонд у фирмы, 0 - в противном случае \\
\hline IRR & (3) & $\begin{array}{l}\text { Внутренняя ставка доходности фонда из базы данных } \\
\text { Thompson Venture Economics (на основе информации от } \\
\text { инвесторов) }\end{array}$ \\
\hline IRR предыдущего фонда & (3) & Внутренняя ставка доходности предыдущего фонда \\
\hline
\end{tabular}




\section{4. Эмпирические результаты}

\section{Детерминанты ЧСА}

В таблице 5 представлен анализ детерминанты ЧСА. В панели А представлен анализ всей выборки (фонды выкупа и венчурные фонды). Результаты для спецификации с фиксированными эффектами для фирм являются гораздо более значимыми и экономически значимыми ввиду большой гетерогенности среди фирм. Поэтому в дальнейшем мы будем обсуждать именно результаты для фиксированных эффектов, а результаты для объединенной регрессии будут приводиться справочно. Согласно таблице 5, за один-два года до открытия нового фонда фирмы увеличивают ЧСА существующих фондов на 15$25 \%$ в год. Более того, после открытия нового фонда в течение двух лет наблюдается снижение ЧСА существующего фонда на 2,5-2,9\% в год.

Необходимо отметить, что коэффициент при лагированной ЧСА является отрицательным и значимым. Это означает, что после открытия нового фонда ЧСА должна снижаться и величина этого снижения пропорционально увеличению ЧСА, которое было до открытия фонда. Это соответствует гипотезам А3 (ЧСА по балансовой стоимости), Б1 (обман инвесторов) и, возможно, А2 (ЧСА как ликвидационная стоимость).

Помимо этого стоит отметить детерминанты ЧСА. Возраст фонда и последовательность фондов (как прокси для опыта и выживаемости) значимы и прямо связаны с ЧСА. Доходность рынка акций имеет асимметричное влияние на ЧСА: эффект сильнее на растущем рынке, чем на падающем. Причем взаимосвязь между ЧСА и доходностью рынка является обратной, что может отражать конкуренцию между частным и публичным рынками капитала. Доходность рынка акций в предыдущие годы имеет меньшее влияние.

Доходность отрасли фондов прямых инвестиций положительно влияет на ЧСА, причем отрицательная доходность имеет более сильное влияние: при отрицательной доходности коэффициент равен 0,7 , а при положительной - 0,1 (=0,7 - 0,6). Таким образом, снижение (рост) доходности ФПИ снижает (увеличивает), при прочих равных условиях, ЧСА всех фондов, что является интересным результатом, поскольку ЧСА отдельного фонда не зависит от доходности всех фондов. С этой точки зрения, ассиметрия влияния доходности отрасли ФПИ на ЧСА имеет интересную интерпретацию: фонды растут по-разному - рост ЧСА между фондами слабо связан, но снижается ЧСА у фондов гораздо синхронее, что может быть связано с поведенческими особенностями инвестирования в ФПИ (например, эффект толпы - herding).

\section{Детерминанты премии}

В таблице 6 представлены результаты анализа будущей доходности существующих фондов. Для этого мы анализируем премию фонда: отношение рыночной стоимости к ЧСА. Под рыночной стоимостью мы подразумеваем сумму дисконтируемых (по ставке S\&P 500) будущих денежных потоков фонда. В качестве контрольных факторов мы используем бинарные переменные открытия нового фонда, возраст и размер фонда, доходность рынка акций и отрасли ФПИ и пр.

Согласно результатам, приведенным в таблице 6 , коэффициент перед $\Delta$ ЧСА $(\mathrm{t}-1)$ является отрицательным и значимым. Следовательно, если в предыдущем году менеджер увеличил ЧСА, то в следующем году у фонда снизится премия или увеличится дисконт. Другими словами, если менеджер искусственно завысил стоимость ЧСА перед открытием фонда, то после открытия увеличится разрыв между рыночной стоимостью и ЧСА, установленной менеджером. 
Таблица 5

\section{Детерминанты чистой стоимости активов}

\begin{tabular}{|c|c|c|c|c|}
\hline \multirow[t]{2}{*}{ Зависимая переменная: $\Delta$ ЧСА (t) } & \multicolumn{4}{|c|}{ Полная выборка (панель А) } \\
\hline & Спец.1 & Спец. 2 & Спец. 3 & Спец. 4 \\
\hline \multirow[t]{2}{*}{ Возраст фонда $(\log )$} & 0,5 & 1,7 & 0,4 & 1,3 \\
\hline & $(1,7)$ & $(5,5)$ & $(1,4)$ & $(4,5)$ \\
\hline \multirow[t]{2}{*}{ Размер фонда $(\log )$} & 0,9 & $-0,9$ & 0,8 & $-1,0$ \\
\hline & $(2,4)$ & $-(1,8)$ & $(2,4)$ & $-(2,0)$ \\
\hline \multirow[t]{2}{*}{ Размер фирмы $(\log )$} & 0,4 & $-0,7$ & 0,2 & $-1,0$ \\
\hline & $(1,2)$ & $-(1,2)$ & $(0,5)$ & $-(1,9)$ \\
\hline \multirow[t]{2}{*}{ Последовательность фондов $(\log )$} & 0,4 & 10,1 & 0,7 & 10,1 \\
\hline & $(0,5)$ & $(3,4)$ & $(0,9)$ & $(3,4)$ \\
\hline \multirow[t]{2}{*}{$\Delta$ ЧCA $(\mathrm{t}-1)$} & 0,02 & $-0,02$ & 0,02 & $-0,01$ \\
\hline & $(3,0)$ & $-(2,6)$ & $(3,5)$ & $-(1,9)$ \\
\hline \multirow[t]{2}{*}{ Доходность фонда $(\log )$} & $-0,6$ & $-3,0$ & $-0,7$ & $-3,1$ \\
\hline & $-(1,5)$ & $-(7,1)$ & $-(1,8)$ & $-(7,3)$ \\
\hline \multirow[t]{2}{*}{ Открытие фонда $<-2$ года } & $-0,5$ & 16,9 & $-0,7$ & 13,4 \\
\hline & $-(0,2)$ & $(1,8)$ & $-(0,2)$ & $(1,5)$ \\
\hline \multirow[t]{2}{*}{ Открытие фонда [-2, -1) } & 0,4 & 17,3 & 1,1 & 15,2 \\
\hline & $(0,1)$ & $(1,9)$ & $(0,4)$ & $(1,7)$ \\
\hline \multirow[t]{2}{*}{ Открытие фонда [-1,0) } & 8,0 & 24,6 & 8,4 & 22,6 \\
\hline & $(2,7)$ & $(2,7)$ & $(3,1)$ & $(2,6)$ \\
\hline \multirow[t]{2}{*}{ Открытие фонда $[0,1)$} & $-3,3$ & $-2,8$ & $-3,9$ & $-2,9$ \\
\hline & $-(3,5)$ & $-(2,7)$ & $-(4,2)$ & $-(2,8)$ \\
\hline \multirow[t]{2}{*}{ Открытие фонда $[1,2]$} & $-3,1$ & $-2,6$ & $-3,4$ & $-2,5$ \\
\hline & $-(3,9)$ & $-(3,0)$ & $-(4,2)$ & $-(2,8)$ \\
\hline \multirow[t]{2}{*}{ Открытие фонда > 2 лет } & $-1,4$ & $-0,8$ & $-1,5$ & $-0,3$ \\
\hline & $-(1,2)$ & $-(0,6)$ & $-(1,3)$ & $-(0,2)$ \\
\hline \multirow[t]{2}{*}{ Доходность рынка акций (t) } & 0,3 & 0,4 & 0,3 & 0,3 \\
\hline & $(3,1)$ & $(3,4)$ & $(10,3)$ & $(8,6)$ \\
\hline \multirow[t]{2}{*}{ Доходность рынка акций (t) - рост } & $-0,8$ & $-1,5$ & & \\
\hline & $-(0,7)$ & $-(1,3)$ & & \\
\hline \multirow[t]{2}{*}{ Доходность рынка акций (t - 1) } & $-0,1$ & $-0,1$ & 0,0 & 0,0 \\
\hline & $-(4,7)$ & $-(5,3)$ & $-(5,4)$ & $-(5,7)$ \\
\hline \multirow[t]{2}{*}{ Доходность отрасли ФПИ (Private Equity) (t) } & 0,6 & 0,7 & 0,1 & 0,1 \\
\hline & $(4,7)$ & $(5,4)$ & $(5,5)$ & $(5,8)$ \\
\hline \multirow[t]{2}{*}{ Доходность отрасли ФПИ (Private Equity) (t) - рост } & $-0,5$ & $-0,6$ & & \\
\hline & $-(3,9)$ & $-(4,6)$ & & \\
\hline \multirow[t]{2}{*}{ Венчурный фонд } & $-2,1$ & $-1,9$ & $-2,1$ & $-1,8$ \\
\hline & $-(2,9)$ & $-(1,2)$ & $-(3,0)$ & $-(1,1)$ \\
\hline \multirow[t]{2}{*}{ Фонд из США } & 1,1 & $-2,1$ & 0,7 & $-1,9$ \\
\hline & $(1,7)$ & $-(0,5)$ & $(1,1)$ & $-(0,4)$ \\
\hline \multirow[t]{2}{*}{ Первый фонд } & $-0,27$ & $-1,88$ & & \\
\hline & $-(0,4)$ & $-(2,2)$ & & \\
\hline Firm fixed effects & & Да & & Да \\
\hline R_2 & $7 \%$ & $14 \%$ & $7 \%$ & $14 \%$ \\
\hline Число наблюдений & 14458 & 14458 & 14458 & 14458 \\
\hline
\end{tabular}


Детерминанты будущей доходности существующих фондов

Таблица 6

\begin{tabular}{|c|c|c|c|c|c|c|}
\hline $\begin{array}{c}\text { Зависимая переменная: } \\
\log (\mathrm{MV} / \mathrm{CA})(\mathrm{t}) \\
\end{array}$ & Спец,1 & Спец, 2 & Спец, 3 & Спец, 4 & Спец, 5 & Спец, 6 \\
\hline \multirow[t]{2}{*}{ Возраст фонда $(\log )$} & 0,00 & 0,00 & 0,00 & 0,00 & 0,00 & 0,00 \\
\hline & $-(8,9)$ & $-(8,3)$ & $-(11,4)$ & $-(10,6)$ & $-(10,5)$ & $-(10,1)$ \\
\hline \multirow[t]{2}{*}{ Размер фонда $(\log )$} & 0,08 & 0,08 & 0,05 & 0,08 & 0,06 & 0,08 \\
\hline & $(9,9)$ & $(9,3)$ & $(6,8)$ & $(8,8)$ & $(8,4)$ & $(9,2)$ \\
\hline \multirow[t]{2}{*}{ Размер фирмы (log) } & $-0,03$ & $-0,09$ & 0,01 & $-0,11$ & $-0,01$ & $-0,10$ \\
\hline & $-(5,7)$ & $-(10,7)$ & $(2,7)$ & $-(12,5)$ & $-(1,5)$ & $-(12,2)$ \\
\hline \multirow[t]{2}{*}{ Последовательность фондов (log) } & 0,13 & 0,26 & 0,06 & 0,25 & 0,09 & 0,25 \\
\hline & $(5,6)$ & $(8,8)$ & $(2,6)$ & $(8,4)$ & $(3,9)$ & $(8,5)$ \\
\hline \multirow[t]{2}{*}{$\Delta$ ЧCA (t-1) } & 0,00 & 0,00 & 0,00 & 0,00 & 0,00 & 0,00 \\
\hline & $(0,5)$ & $-(4,1)$ & $(0,4)$ & $-(3,7)$ & $-(2,1)$ & $-(5,7)$ \\
\hline \multirow[t]{2}{*}{ Открытие фонда $<-2$ года } & $-0,1$ & $-0,1$ & $-0,2$ & $-0,2$ & $-0,2$ & $-0,2$ \\
\hline & $-(6,1)$ & $-(5,6)$ & $-(8,4)$ & $-(8,3)$ & $-(8,0)$ & $-(8,0)$ \\
\hline \multirow[t]{2}{*}{ Открытие фонда $[-2,-1)$} & 0,0 & 0,0 & 0,1 & 0,0 & 0,1 & 0,0 \\
\hline & $(0,9)$ & $(0,4)$ & $(3,1)$ & $(0,8)$ & $(2,3)$ & $(0,8)$ \\
\hline \multirow[t]{2}{*}{ Открытие фонда [-1,0) } & $-0,1$ & $-0,1$ & $-0,2$ & $-0,2$ & $-0,2$ & $-0,1$ \\
\hline & $-(5,6)$ & $-(4,5)$ & $-(7,2)$ & $-(6,0)$ & $-(6,8)$ & $-(5,6)$ \\
\hline \multirow[t]{2}{*}{ Открытие фонда $[0,1)$} & $-0,1$ & $-0,1$ & $-0,1$ & $-0,1$ & $-0,1$ & $-0,1$ \\
\hline & $-(4,6)$ & $-(3,4)$ & $-(4,6)$ & $-(4,2)$ & $-(4,6)$ & $-(3,8)$ \\
\hline \multirow[t]{2}{*}{ Открытие фонда $[1,2]$} & 0,0 & 0,0 & 0,0 & 0,0 & 0,0 & 0,0 \\
\hline & $-(0,1)$ & $(0,8)$ & $(1,7)$ & $(1,1)$ & $(1,0)$ & $(1,1)$ \\
\hline \multirow[t]{2}{*}{ Открытие фонда >2 лет } & $-0,1$ & $-0,1$ & $-0,1$ & $-0,1$ & $-0,1$ & $-0,1$ \\
\hline & $-(3,6)$ & $-(3,8)$ & $-(4,1)$ & $-(4,2)$ & $-(3,8)$ & $-(3,9)$ \\
\hline \multirow[t]{2}{*}{ Доходность рынка акций (t) } & $-0,03$ & $-0,03$ & 0,09 & 0,06 & 0,02 & 0,02 \\
\hline & $-(4,3)$ & $-(3,8)$ & $(15,4)$ & $(10,4)$ & $(3,6)$ & $(3,6)$ \\
\hline \multirow[t]{2}{*}{ Доходность рынка акций (t) - рост } & 0,4 & 0,3 & & & & \\
\hline & $(15,8)$ & $(14,2)$ & & & & \\
\hline \multirow[t]{2}{*}{ Доходность рынка акций (t - 1) } & 0,0 & 0,0 & 0,0 & 0,0 & 0,0 & 0,0 \\
\hline & $-(3,4)$ & $-(2,2)$ & $-(3,8)$ & $-(1,9)$ & $-(4,3)$ & $-(2,5)$ \\
\hline \multirow[t]{2}{*}{$\begin{array}{llll}\text { Доходность } & \text { отрасли } & \text { ФПИ } & \text { (Private } \\
\text { Equity) }(\mathrm{t}) & & & \\
\end{array}$} & 0,0 & 0,0 & 0,0 & 0,0 & & \\
\hline & $-(16,0)$ & $-(14,2)$ & $-(5,0)$ & $-(4,8)$ & & \\
\hline \multirow[t]{2}{*}{$\begin{array}{llll}\text { Доходность отрасли } & \text { ФПИ } & \text { (Private } \\
\text { Equity) }(\mathrm{t})-\text { рост } & & \\
\end{array}$} & 0,4 & 0,3 & & & 0,3 & 0,1 \\
\hline & $(14,6)$ & $(11,9)$ & & & $(12,1)$ & $(6,7)$ \\
\hline \multirow[t]{2}{*}{ Венчурный фонд } & 0,0 & $-0,1$ & 0,1 & $-0,1$ & 0,1 & $-0,1$ \\
\hline & $(3,1)$ & $-(3,8)$ & $(8,7)$ & $-(3,6)$ & $(6,8)$ & $-(3,4)$ \\
\hline \multirow[t]{2}{*}{ Фонд из США } & 0,1 & $-0,1$ & 0,1 & $-0,1$ & 0,1 & $-0,1$ \\
\hline & $(4,6)$ & $-(2,2)$ & $(4,2)$ & $-(2,3)$ & $(4,1)$ & $-(2,3)$ \\
\hline \multirow[t]{2}{*}{ Первый фонд } & 0,1 & 0,0 & 0,1 & 0,0 & 0,1 & 0,0 \\
\hline & $(3,4)$ & $(1,2)$ & $(7,3)$ & $(3,0)$ & $(5,7)$ & $(2,5)$ \\
\hline Firm fixed effects & & Да & & Да & & Да \\
\hline R_2 & $16 \%$ & $32 \%$ & $12 \%$ & $30 \%$ & $13 \%$ & $30 \%$ \\
\hline Число наблюдений & 11692 & 11692 & 11692 & 11692 & 11692 & 11692 \\
\hline
\end{tabular}


Одно из возможных объяснений - способность больших фирм сильнее увеличивать ЧСА, поскольку они имеет больше власти над инвесторами (особенно небольшими инвесторами) в виду своего размера.

Отрицательный знак возраста фонда может быть объяснен связью между доходность фонда и длительностью инвестиций, обнаруженной Фалиппуи Госхальдом [Phalippou and Gottschalg, 2006].

Рынок акций и доходность отрасли ФПИ влияют положительно на премию, при этом, отрицательная доходность имеет гораздо меньший эффект. Размер фонда и последовательность фонда влияют положительно на премию.

Таким образом, это соответствует гипотезам А3 (ЧСА по балансовой стоимости) и Б1 (обман инвесторов).

\section{Размер нового фонда}

Согласно результатам, представленными в таблице 7, размер нового фонда зависит положительно от размера предыдущего фонда (эластичность - 0,77), опыта (последовательность фондов) и предыдущей доходности (IRR предыдущего фонда) ${ }^{14}$. Удивительно, но конечный IRR ${ }^{15}$ нового фонда не влияет на его размер. Таким образом, инвесторы не могут предсказать конечную IRR фонда, в который они инвестируют, и принимают решение на основание IRR предыдущего фонда. Используя этот факт, менеджеры могут открывать фонды большего размера, завышая значения IRR предыдущего фонда.

Помимо этого остается открытым вопрос о роли IRR как меры доходности фондов. Хорошо известно, что инвесторы обычно используют две меры при принятии решения IRR и денежный мультипликатор.

\footnotetext{
14 Первые два результата соответствует гипотезе Берка и Грина [Berk and Green, 2005] о том, что более доходные фонды и/или фонды с хорошей репутацией доходностей должны быть большего размера. Результаты также совпадают с результатами Каплана и Шора [Kaplan and Schoar, 2005].

${ }^{15}$ Имеется ввиду IRR фонда за весь период его существования.
} 


\section{Размер новых фондов}

\begin{tabular}{|c|c|c|c|c|}
\hline Зависимая переменная: $\log$ (размер фонда) & Спец.1 & Спец. 2 & Спец. 3 & Спец. 4 \\
\hline \multirow[t]{2}{*}{$\Delta \mathrm{YCA}(\mathrm{t}-1)$} & 0,022 & $-0,019$ & 0,025 & $-0,142$ \\
\hline & $(0,8)$ & $(1,1)$ & $(0,8)$ & $(1,2)$ \\
\hline \multirow[t]{2}{*}{ Последовательность фондов $(\log )$} & 0,874 & 0,878 & 2,648 & 2,652 \\
\hline & $(13,8)$ & $(13,9)$ & $(49,4)$ & $(49,8)$ \\
\hline \multirow[t]{2}{*}{ IRR } & $-0,001$ & $-0,001$ & $-0,001$ & $-0,001$ \\
\hline & $-(1,0)$ & $-(0,9)$ & $-(0,9)$ & $-(0,8)$ \\
\hline \multirow[t]{2}{*}{ Размер предыдущего фонда $(\log )$} & 0,766 & 0,766 & & \\
\hline & 37,426 & 37,513 & & \\
\hline \multirow[t]{2}{*}{ IRR предыдущего фонда (log) } & 0,002 & 0,002 & 0,003 & 0,003 \\
\hline & $(3,1)$ & $(3,3)$ & $(3,6)$ & $(3,8)$ \\
\hline \multirow[t]{2}{*}{ Первый фонд } & 3,953 & 3,938 & 2,095 & 2,076 \\
\hline & $(55,5)$ & $(55,5)$ & $(32,2)$ & $(32,1)$ \\
\hline \multirow[t]{2}{*}{ Доходность рынка акций (t) } & $-0,004$ & $-0,004$ & $-0,009$ & $-0,008$ \\
\hline & $-(2,0)$ & $-(2,2)$ & $-(3,5)$ & $-(3,5)$ \\
\hline \multirow[t]{2}{*}{ Доходность рынка акций (t - 1) } & 0,000 & 0,000 & 0,000 & 0,000 \\
\hline & $-(2,3)$ & $-(4,0)$ & $-(1,4)$ & $-(2,8)$ \\
\hline \multirow[t]{2}{*}{ Доходность рынка акций (t - 2) } & 0,000 & 0,000 & 0,000 & 0,000 \\
\hline & $(2,2)$ & $(3,3)$ & $(1,4)$ & $(2,2)$ \\
\hline \multirow[t]{2}{*}{ Доходность рынка акций (t - 3) } & 0,000 & 0,000 & 0,000 & 0,000 \\
\hline & $(2,3)$ & $(4,0)$ & $(1,4)$ & $(2,8)$ \\
\hline \multirow[t]{2}{*}{ Венчурный фонд } & $-0,463$ & $-0,446$ & $-0,658$ & $-0,643$ \\
\hline & $-(9,3)$ & $-(9,3)$ & $-(10,4)$ & $-(10,6)$ \\
\hline \multirow[t]{2}{*}{ Фонд из США } & $-0,495$ & $-0,532$ & $-0,507$ & $-0,547$ \\
\hline & $-(10,6)$ & $-(11,5)$ & $-(8,5)$ & $-(9,3)$ \\
\hline Time Effect & Да & & Да & \\
\hline R_2 & $73 \%$ & $73 \%$ & $56 \%$ & $56 \%$ \\
\hline Число наблюдений & 2279 & 2279 & 2279 & 2279 \\
\hline
\end{tabular}

Эти же меры публикуют менеджеры в инвестиционных меморандумах. Причем обе эти меры являются неполноценными, обманчивыми, ими легко манипулировать с точки зрения анализа доходности фонда. Фалиппу [Phalippou, 2008] проанализировал основные недостатки IRR и пришел к выводу о неприменимости IRR для анализа доходности ФПИ и выбора фонда, ввиду того что IRR не отражает эффективной ставки доходности инвестирования в ФПИ, а также из-за способности менеджеров манипулировать оценкой IRR. Учитывая это, остается загадкой, почему существует сильная зависимость между IRR предыдущего фонда и размером нового фонда: с одной стороны, данная зависимость может быть лишь статистическим миражом или результатом другой, более сложной взаимосвязи; с другой стороны, инвесторы, при отсутствии альтернативной метрики, могут «верить» в IRR, публикуемые менеджментом.

Первый фонд ${ }^{16}$ имеет, при прочих равных, больший размер. Это может быть объяснено с помощью гипотезы реального опциона, при которой инвесторы стараются участвовать в молодых, менее опытных и, как правило, менее прибыльных фондах, с тем чтобы выстроить отношения с менеджментов этих новых фондов. Эти отношения являются ценным опционом, поскольку, если менеджмент окажется высокоэффективным, у инвесторов есть

\footnotetext{
${ }^{16}$ Имеется в виду ситуация, когда фирма в первый раз открывает фонд.

Выпуск \#4(8), 2008 С Электронный журнал Корпоративные Финансы, 2008
} 
возможность подписаться (участвовать) на новый фонд, минуя общую очередь ${ }^{17}$.

Размер фонда также зависит от доходности рынка акций: за один год до открытия и в год открытия фонда существует отрицательный эффект. То есть чем быстрее растет в момент открытия рынок акций, тем меньшего размера будет фонд, что отражает конкуренцию между публичным рынком капитала и ФПИ. Похожая зависимость была найдена Гомперсом и др. [Gompers et al., 2005].

Таким образом, это соответствует гипотезам А1 (ЧСА как рыночная стоимость), А3 (ЧСА по балансовой стоимости) и Б1 (обман инвесторов).

\section{Выводы}

В результате только одна гипотеза соответствует наблюдаемым данным - гипотеза «манипулирование инвесторами», подгипотеза «менеджеры всегда преувеличивают ЧСА». Стоит отметить, что полученный результат чувствителен к результатам последней модели. Более того, анализ робастности показывает, что результаты первой модели чувствительны к выборке.

\section{Список литературы}

1. Gompers P., Kovner A., Lerner J., and Scharfstein D. Venture Capital Investment Cycles: The Impact of Public Markets // NBER Working Paper. 2005. No. 11385.

2. Phalippou Ludovic. The Hazards of Using IRR to Measure Performance: The Case of Private Equity // Available at SSRN: http://ssrn.com/abstract=1111796. 2008.

3. Phalippou L., and O. Gottschalg. The Performance of Private Equity Funds //Working paper, University of Amsterdam and HEC Paris. 2006.

4. Berk J., Green R. Mutual Fund Flows and Performance in Rational Markets // Journal of Political Economy. 2004. Vol, 112. No. 6. P.1269-295.

5. Kaplan S., Schoar A. Private Equity Performance: Returns, Persistence and Capital Flows. AFA 2004 San Diego Meetings // MIT Sloan Working Paper. 2003. No. 4446-03.

17 Успешные фонды имеют большую очередь, состоящую из инвесторов, желающих вложить средства. Учитывая, что фонд, как правило, имеет фиксированный размер, части инвесторов будет отказано в участия в фонде. 